Berthet, A. ; de Batz, A. ; Tardif, R. ; Charest-Tardif, G. ; Truchon, G. ; Vernez, D.; Droz, P.O. Impact of biological and environmental variabilities on biological monitoring: an approach using toxicokinetic models. Journal of Occupational and Environmental Hygiene, 7(3):177-184, 2010 .

\begin{tabular}{|l|l|}
\hline Postprint version & Final draft post-refereeing \\
\hline Journal website & http://www.tandf.co.uk/journals/titles/15459624.asp \\
\hline Pubmed link & http://www.ncbi.nlm.nih.gov/pubmed/20063230 \\
\hline DOI & $10.1080 / 15459620903530052$ \\
\hline
\end{tabular}




\title{
IMPACT OF BIOLOGICAL AND ENVIRONMENTAL VARIABILITIES ON BIOLOGICAL MONITORING. AN APPROACH USING TOXICOKINETIC MODELS
}

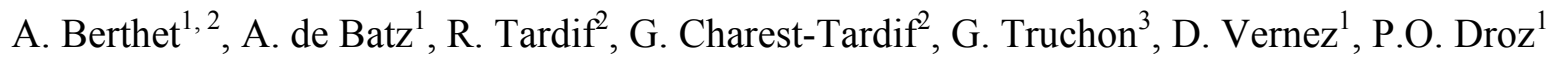 \\ ${ }^{1}$ Institute for Work and Health, Lausanne University, Lausanne, Switzerland \\ ${ }^{2}$ Département de santé environnementale et santé au travail, Université de Montréal, Québec, \\ Canada \\ ${ }^{3}$ Institut de recherche Robert-Sauvé en santé et en sécurité du travail (IRSST), Montréal, Québec, \\ Canada
}

\author{
Corresponding author \\ Aurélie Berthet \\ Institute for Work and Health \\ Lausanne University \\ Rue du Bugnon 21 \\ CH-1011 Lausanne, Switzerland \\ Tel: +41 21-314-7468 \\ Fax: +41 21-314-7420 \\ Email: aurelie.berthet@hospvd.ch
}

Keywords: toxicokinetic compartmental model; environmental variability; total variability; exposure monitoring; biological monitoring of exposure.

Word count of the exposition only: 3,344 words 


\section{SUMMARY}

Context. Biological monitoring of occupational exposure is characterized by important variability, due to both variability in the environment and to biological differences between workers. A quantitative description and understanding of this variability is important for a dependable application of biological monitoring. The purpose of this work was to describe this variability, using a toxicokinetic model, for a large range of chemicals for which reference biological reference values exist.

Methods. A toxicokinetic compartmental model describing both the parent compound and its metabolites was used. For each chemical, compartments were given physiological meaning. Models were elaborated based on physiological, physico-chemical and biochemical data when available, and on half-lives and central compartment concentrations when not available. Fourteen chemicals were studied (arsenic, cadmium, carbon monoxide, chromium, cobalt, ethylbenzene, ethyleneglycol monomethylether, fluorides, lead, mercury, methyl isobutyl ketone, penthachlorophenol, phenol and toluene), representing 20 biological indicators. Occupational exposures were simulated using Monte Carlo techniques with realistic distributions of both individual physiological parameters and exposure conditions. Resulting biological indicator levels were then analyzed to identify the contribution of environmental and biological variability to total variability.

Results and Conclusion. Comparison of predicted biological indicator levels with biological exposure limits showed a high correlation with the model for 19 out of 20 indicators. Variability associated to changes in exposure levels (GSD of 1.5 and 2.0) is shown to be mainly influenced 
by the kinetics of the biological indicator. Thus, with regard to variability, we can conclude that, for the fourteen chemicals modeled, biological monitoring would be preferable to air monitoring. For short half-lives (less than 7 hours) this is very similar to the environmental variability. However, for longer half-lives, estimated variability decreased.

Keywords: toxicokinetic compartmental model; environmental variability; total variability; exposure monitoring; biological monitoring of exposure.

\section{INTRODUCTION}

Occupational exposure assessment is an important step in managing chemical exposure in the workplace. Because inhalation is often the predominant route of exposure, this assessment very often relies on measurements of the air which workers are breathing. In many instances, biological monitoring of exposure is also used, and this is considered to better represent exposure because it takes into account such factors as the physical workload, other exposure routes, and differences in distribution and metabolism. ${ }^{(1,2)}$

Air monitoring results have been shown to present important variability whether repeated measurements are taken for the same worker, the same workplace or the same industry. ${ }^{(3,4)}$ This variability can be divided into within-worker variability (the same worker from day to day) and between-worker variability (differences in long term average exposure between

workers). ${ }^{(5)}$ When using biological monitoring data an additional source of variability has to be considered: individual variability due to physiological and biochemical differences both within 
and between workers. This aspect was recently studied by our group for a number of chemical agents using physiologically based toxicokinetic and compartmental toxicokinetic models. ${ }^{(6,7)}$

In field situations, biological monitoring results are thus affected by both individual variability and environmental variability. Based on the analysis of a large database of $\underline{\text { occupational and environmental biological and air monitoring measurements, Lin et al } .^{(4)}}$ demonstrated that biological data show less variability than air sampling results. This was further shown to be associated with the kinetics of the biological indicator. Similar trends were obtained in a previous study using simple toxicokinetic considerations. ${ }^{\left({ }^{(8)}\right.}$ These exploratory analyses were made in the context of retrospective exposure assessment for epidemiological studies.

An in depth description and understanding of the simultaneous effects of the environmental and individual variability on the bioindicators also appears to be recommended for the practical application of biological monitoring techniques. The conclusion which can be drawn from the results obtained and the decisions as to which monitoring technique should be used in a particular situation are important parts of the exposure assessment process. Thus, it is important to have a good understanding of the associated variability for the application of biological monitoring in the evaluation of current occupational exposure. This was previously described for exposures at steady concentrations (i.e. considering only individual variability) using physiologically based toxicokinetic modelling (PBTK) and compartmental toxicokinetic models. ${ }^{(9,10)}$ The purpose of the present study was to extend the application of the compartmental toxicokinetic models to include environmental variability in the discussion of biological monitoring variability. 
Using toxicokinetic tools developed previously by our group ${ }^{(10)}$, the objective of this paper is to describe the total variability observed in biological monitoring results under field conditions as a function of environmental and individual variability. This approach was applied to 14 widely used chemical compounds and their twenty related biological indicators.

\section{METHODS}

\section{Model Description}

A compartmental based toxicokinetic (CBTK) model developed for several chemicals in a previous study ${ }^{(10)}$ was used to assess the effect of individual and environmental variability on bioindicator results. The model structure, presented in Figure 1, is a compromise between the detailed biological processes and the availability of data for a wide range of chemicals. This generic model was applied to 14 chemicals chosen from the IRSST's guide to corresponding biological indicators. Specifically, the chemicals were: arsenic, cadmium, carbon monoxide, chromium, cobalt, ethylbenzene, ethyleneglycol monomethylether, fluorides, lead, mercury, methyl isobutyl ketone (MIBK), penthachlorophenol, phenol and toluene. Physiological, physicochemical, biochemical and kinetic data were used to simulate the behavior of each chemical in the human body. The values of the model parameters were modulated according to each compound's basic data.

The generic CBTK model is composed of two compartments: central (C) and peripheral (P) physiological compartments. Elimination is represented by two kinetic relationships: for

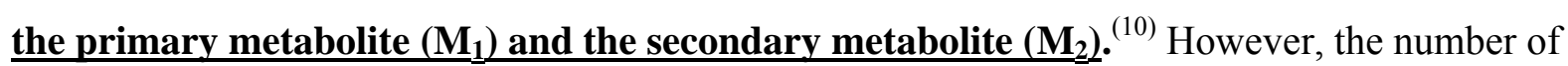


compartments used depends on the chemical, it may vary from one to four depending on the available data on the compound and its toxicokinetic behavior.

In these models, the absorption, excretion and exchanges between compartments are described by flows. Uptake occurs in compartment C. The initial substance is then distributed to compartment $\mathrm{P}$ according to the blood flow $(\mathrm{BF})$ rate, the estimated volume of the compartment (e.g. kidney or liver volume), the partition coefficients, and the compartment burden. This distribution also depends on the permeability of the tissue to the substance and it can therefore be perfusion or diffusion limited. The transfer between the compartment $\mathrm{C}$ and the metabolite compartments is described by the metabolic clearance. The flux between the compartment $\mathrm{C}$ and metabolites is calculated as a function of the organ's blood flow, the Michaelis-Menten constant, and the maximum rate of metabolism. It was considered to be a first-order kinetic in the range of concentrations obtained during the exposures which we simulated, as they are in most cases low and limited in range (a factor of 10, at most). The model structure also allows the description of the transformation of one metabolite into another, i.e. serial metabolism. In this case, the kinetics of the secondary metabolite depends on the burden of primary metabolite and on its metabolic clearance. Finally, elimination is considered to occur through pulmonary, fecal and urinary excretion, as well as by metabolism.

The general structure of the model was adapted for each substance selected with regards to the known metabolites, and the available data concerning physiological and biochemical mechanisms. Model mathematical equations have been presented and discussed previously ${ }^{(10)}$.

\section{Model Parameters}


Models were established using physiological and biochemical parameters. The specific structure and data used for each chemical are presented in detail in Table IV (Appendix). This indicates which compartments were considered and the specific parameters used for the chemical of interest. Generic parameters are presented in Table I: cardiac output, alveolar ventilation, body weight, creatinine excretion and urine output. These were taken to vary as a power function of body weight. Table I also displays coefficients of variation (CV) and parameter distributions for biological parameters considered as random variables. They were selected from a literature review or from data of Thomas et al. ${ }^{(13)}$. These random variables were then used to calculate the parameters specific to each chemical as presented in Table IV (Appendix).

In some cases, parameters determining the flows had to be estimated from elimination halflife $\left(t^{1} / 2\right)$ and sometimes compartment steady-state concentrations. Depending on the chemical, specific parameters estimated were: tissue volume, tissue permeability, and urinary and feces excretion rate constants.

All data used in the specific models are summarized in Table IV, together with a description of the compartments used. We initially searched for useful basic toxicokinetic information in $\underline{\text { review articles }}{ }^{(14,15,16)}$, and further specific information was extracted from other literature (see footnotes in Table IV (Appendix)).

\section{Model Evaluation}


Results from the model were compared to actual concentrations measured in humans, notably under conditions representative of occupational exposure. No formal evaluation was made. Best fit was not attempted, but a reasonable correlation was looked for by visually comparing results with measured data at different time points. To validate the models, we estimated what biological concentrations would be following repeated exposure at the occupational exposure limit (OEL). The results obtained at specified sampling times were compared to corresponding biological exposure indices $(\mathrm{BEI})^{(14)}$. Although, by definition, the latter are not directly linked to OEL, in most cases they represent a good estimation of real life exposure.

\section{Monte Carlo Simulations}

After obtaining a valid model for an average worker, for a given chemical, the second step consists of simulating different scenarios (different individuals, different exposure conditions, etc.). The simulations modeled workers carrying out a physical activity of 50 Watts for 12 hours per day (eight hours of work activity with exposure followed by four hours of activity

outside work). This was followed by a rest period of 12 hours. A normal week consisted of five successive days of eight hours exposure followed by two unexposed days. The parameters dependant on physical activity (cardiac output, alveolar ventilation, organ blood flows, etc.) were adjusted to correspond to this daily pattern.

The data set was generated by two-dimensional (2D) Monte Carlo simulations. This model simulated both uncertainty and variability in distribution parameters, unlike onedimensional Monte Carlo (1D) analysis that would model either uncertainty or variability 
in input variable. ${ }^{(17)}$ The software used for programming the simulation was SAS V9.1 (SAS Institute Inc). The modeling equations were solved using the Euler method. Previous studies have presented these in detail. $^{(10)}$

\section{Sample Size}

In order to optimize modeling studies, preliminary simulations were done to estimate the minimum number of simulated days (sample) required to represent the statistical parameters of a population with a given confidence interval. These preliminary simulations were run for chemicals on the BEI which had shown the most variability in previous studies. ${ }^{(6,7)}$ The population was described by simulating a group of 500 similar workers subject to 100 weeks of exposure, with an average exposure variability (GSD of 2.0). Exposure was fixed so that $95 \%$ of daily exposures were below the OEL. The 50,000 observations collected (one biological sample taken each week, for each worker) were computed and statistically analyzed to determine the population variance $\left(\mathrm{s}^{2}\right)$. The minimum required sample, size $\mathrm{N}$ (uncorrected sample size estimate), was calculated with a target precision level "B"(18) such that:

$$
\mathrm{N}=1.96^{2 *} \mathrm{~s}^{2} / \mathrm{B}^{2}
$$

$\mathrm{B}$ is expressed as half of the maximum acceptable confidence interval width. At the end-of-shift exposure analysis, the most variable biological indicator proved to be toluene in the blood. To ensure a statistically representative estimation of the " 50,000 " population distribution, with a $10 \%$ precision level, the resulting sample size was 229 weeks. The number of observations was thus fixed at 300 weeks for all chemicals, corresponding to a total of 1,500 daily exposures generated randomly. 


\section{Exposure Scenarios}

Three types of output parameters are required to assess the variability of bioindicators: the biological variability $\left(\mathrm{BV}_{\mathrm{B}}\right)$, the environmental biological variability $\left(\mathrm{BV}_{\mathrm{E}}\right)$ and the total variability $\left(\mathrm{BV}_{\mathrm{T}}\right)$.

The $\mathrm{BV}_{\mathrm{B}}$ is defined as the variability in the bioindicators associated with variations in physiological parameters between workers in a constant exposure scenario. In this study, individual within-worker variability was considered much smaller than between-worker variability and for simplicity was therefore ignored (no intra-individual biological variability). ${ }^{(19)}$

The $\mathrm{BV}_{\mathrm{E}}$ is defined as the variability in the biological indicators due to the variations in the exposure scenario for a given worker exposed to stable ambient concentrations during the day, but varying day to day. This was simulated by the exposure of the average worker for 300 weeks, using two exposure patterns (GSD of 1.5 and GSD of 2.0). Thus, in this case the environmental variability was the only influence on biological monitoring. The GSD of 1.5 and GSD of 2.0 were chosen to represent typical low and average environmental variabilities. ${ }^{(20)}$

The $\mathrm{BV}_{\mathrm{T}}$ is defined as the variability of the bioindicator data in a group of workers exposed to varying daily concentrations. This represents the combined $B V_{B}$ and $B V_{E}$. This was estimated by simulating 500 biologically different workers exposed to varying airborne concentrations over 1,500 days. 


\section{Statistical Analysis}

The results obtained in the different scenarios for the various biological indicators were statistically analyzed using SAS V9.1. The normality of the data distributions and of the logarithmically transformed data were verified using the Kolmogorov-Smirnov-Goodness-of-fit Test. The skewness and the kurtosis were estimated for each distribution. Descriptive geometric statistics (geometric mean, GSD and the lower and upper limits of confidence intervals) were also compiled for each biological indicator distribution.

To facilitate the analysis and the use of the results, the Upper Confidence Index (UCI) was calculated. This can be used to assess the upper confidence limit $\mathrm{UCL}_{95}$ associated with a biological monitoring result (RS), for each biological indicator:

$$
\begin{aligned}
& \mathrm{UCI}=\operatorname{GSD}_{i i}(1.96 / \sqrt{n}) \\
& \mathrm{UCL}_{95}=\mathrm{RS} \times \mathrm{UCI}
\end{aligned}
$$

where ii could represent $\mathrm{BV}_{\mathrm{E}}, \mathrm{BV}_{\mathrm{B}}$ or $\mathrm{BV}$, and $\mathrm{n}$ is the number of measurements completed (if $\mathrm{n}$ $>1$, RS is the geometrical mean).

\section{RESULTS AND DISCUSSION}

\section{Predicting BEIs with the CBTK Model}


Table II shows the biological concentrations obtained for exposures at the OEL with the CBTK model using general data from Table I and chemical-specific information from Table IV (Appendix). The data shown are for sampling times and biological fluids specified for the given BEI. On average, the CBTK model overestimates the corresponding BEIs by $12 \%$, with a range from -35 to $105 \%$. A fair correlation was obtained between predicted results and the recommended BEIs, except for with methyl isobutyl ketone (MIBK). The discrepancy for MIBK (105\% higher than the BEI) might also come from uncertainties in the BEI value itself, as indicated by the higher limit value $(35 \mathrm{mmol} / \mathrm{l})$ proposed in Germany. ${ }^{(21)} \mathrm{A}$ simple compartmental model, based on accessible physiological, physico-chemical and biochemical data, can thus be used to predict biological levels corresponding fairly accurately to OELs.

\section{Furthermore, results rest on a realistic representation of the model, thus we can be}

confident in their mean and variability results. The model requires not more than 12 parameters which can be estimated from physiological and metabolic information. Such models could easily be applied to other less studied chemicals to gather information on potential biological levels at the OEL, and their associated variability.

\section{Biological Variability}

According to the Kolmogorov-Smirnov test, the majority of the distributions obtained for the different biological indicators in the different exposure scenarios were lognormal. After logarithmic transformation, distributions proved to be normal, with nearly no skewness or kurtosis, except for cadmium (GSD of 1.5 and GSD of 2.0) and for fluorides (GSD of 1.5). Indeed, these two BEIs did not fit a normal distribution after logarithmic transformation of data, and skewness and kurtosis were very high in some cases. It must be noted that these two 
biological indicators have very long half-lives, which could explain the non-lognormal behavior. In this case, biological levels likely represent more long term mean exposure than current exposure (or at least a mix of long term and recent exposure) and are therefore minimally influenced by the lognormal daily fluctuations in exposure concentration (especially in the case of a GSD of 1.5).

The results of the estimated variabilities are reported in Table III. They are presented in the form of GSDs to allow a better comparison with simulated exposure variability (GSD of 1.5 and GSD of 2.0). Three variabilities are presented: (1) $\mathrm{BV}_{\mathrm{B}}$, the variability in biological results that would be observed in a group of different workers exposed to the same daily concentration (exposure GSD of 2.0, with no within-worker exposure variability); (2) $\mathbf{B V}_{\mathbf{E}}$, the variability in biological results that is predicted in a group of identical workers exposed to the same long term exposure concentration (no between-worker exposure variability), but at exposures fluctuating from day-to-day; and (3) $\mathrm{BV}_{\mathrm{T}}$ the variability in biological results that would be observed in a group of different workers at exposures fluctuating from day-to-day. Both $\underline{B V}_{\underline{E}} \underline{\text { and }} \mathrm{BV}_{\mathrm{T}} \underline{\text { were investigated for small (GSD of 1.5) and average (GSD of 2.0) variation }}$ in the exposure scenarios. When comparing $B V_{B}$ and $B V_{E}$ with $B V_{T}$, we can estimate the contribution of individual variability to the total variability observed in biological monitoring results.

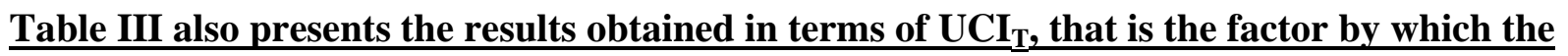
measurements (e.g. blood toluene) have to be multiplied to obtain their upper $95 \%$ statistical confidence limit. This gives an idea of the potential variability to be expected for a given biological indicator measurement, based on total variability. 
For $\mathbf{B V}_{\mathbf{E}}$, results display that the urinary indicators with short half-lives (less than 7 hours) (e.g. urinary MIBK) have a variability similar, but always inferior to the variability of the contaminant concentrations in air. For the other biological indicators (blood or urinary parameters with longer half-lives) (e.g. blood/urinary colbalt), the variability observed in biological results is much lower than that of ambient air levels. This tendency is noticeable for GSDs of both 1.5 and 2.0 exposure patterns. For the GSD of 2.0 exposure pattern, most biological indicators had a $\mathrm{BV}_{\mathrm{E}}$ much lower than 2.0. However, five urinary parameters associated with short half-lives (chromium, MIBK, toluene (urinary ortho-cresol), carbon monoxide and phenol) were shown to be close to 2.0 (although lower). This general reduction of variability compared to exposure variability is associated with the smoothing effect of biological processes. However, observed total biological variability will, in practice, be a combination of $\mathrm{BV}_{\mathrm{B}}$ and $\mathrm{BV} \mathrm{E}_{\mathrm{E}}$, and could in some cases be larger than exposure variability itself.

Data in Table III also suggest that there is a link between the predicted $\mathrm{BV}_{\mathrm{E}}$ and the biological half-lives. This is further illustrated in Figure 2, where dominant half-life is compared to $\mathrm{BV}_{\mathrm{E}}$. The variability in the biological indicators due to the variations in the exposure scenario tends to decrease with the chemical half-life. This is in qualitative agreement with what was previously shown in a simple one-compartment model $^{(8)}$ and should be taken into account when interpreting biological monitoring data, and defining an action level to take decisions. These results suggest that using biological monitoring does not offer a significant advantage for chemicals with short half-life. That is particularly true for chemical with a half-life shorter than the duration of a work day. As a matter of fact, the exposure model used in this paper assumes stable ambient concentrations during the day. In real-life conditions, the ambient concentrations may vary 
greatly throughout the day and hence increase the biological variability of chemicals with short half-lives. For other biological indicators with $\underline{\text { half-lives }}$ of more than 24 hours $\underline{\text { e.g. blood }}$ lead), there is a substantial reduction of variability, making the estimation of long term mean exposure statistically more efficient.

\section{CONCLUSION}

Data obtained in this project allowed for the theoretical comparison between the variability affecting air monitoring and biological monitoring data. Two exposure patterns were selected and were used to evaluate the variability in bioindicators: one which corresponds to low variations in the ambient levels of contaminants (GSD of 1.5) and the other characterized by average variations (GSD of 2.0 ).

According to results from Table III, environmental monitoring seems to be the approach to favor when working environments present small fluctuations in the contaminants studied at ambient levels, except when they have long half-lives in blood. In that exception, the measurement of biological indicators could be better than environmental monitoring because of the smoothing effect of biological indicators with long half-lives.

Furthermore, Droz and $\mathrm{Wu}^{(8)}$ drew a similar conclusion; biological monitoring is the best method when there are significant fluctuations in the ambient levels of exposure and when parameters have a half-life longer than 10 hours. Likewise, the studies by Rappaport et al. ${ }^{(22)}$ and Symanski et al. ${ }^{(23)}$ emphase that biological monitoring data, estimated on the basis of 
measurements of bioindicators with long half-lives, appear to be less variable than air monitoring data, whereas the latter is the best approach to adopt for compounds with short half-lives.

Moreover, measurements of bioindicators with long half-lives may be influenced by individual variability. This would introduce uncertainty in exposure estimation and increase the total variability, whatever the kinetics of the biological indicator. Thus, the total variability observed, which is a combination of and the contribution of individual variability and the exposure estimation, should be considered in the final application of biological monitoring for exposure monitoring.

The decision to adopt biological monitoring should not only rest on variability associated with indicator measurements, but should also take into account the toxicological significance of the biological parameter. The utility of biological monitoring will rest on whether this variability reflects differences in the level of the risk incurred. In spite of the risk of great variability, other situations can also justify the use of alternatives to biological monitoring.

The present study did not take into consideration the simulation of intra-individual variability (biological changes from one day to the next). This was judged to be less important than inter-individual variability. ${ }^{(19)}$ This issue should be considered in further work so as to complete the picture on variability.

The variability data obtained in the present study can be used in order to calculate the number of biological samples required to acquire a given degree of confidence to support 
decision-making. The information presented here should be used as a basis for the development of biological monitoring strategies.

\section{ACKNOWLEDGMENT}

This work was supported by the Institut de recherche Robert-Sauvé en santé et en sécurité du travail (IRSST).

\section{REFERENCES}

1. Lauwerys, R.R., and P. Hoet: Industrial Chemical Exposure. Guidelines for Biological Monitoring, 2nd edition. Boca Raton: Lewis Publishers, 1993.

2. National Academy of Science (NAS): Human biomonitoring for environmental chemicals. Washington DC: The National Academies Press, 2006.

3. Kromhout, H., E. Symansky, and S.M. Rappaport: Comprehensive evaluation of withinand between-worker components of occupational exposure to chemical agents. Ann. Occup. Hyg. 37(3):253-270 (1993).

4. Lin, Y.S., L.L. Kupper, and S.M. Rappaport: Air sample versus biomarkers for epidemiology. Occup. Environ. Med. 62:750-760 (2005). 
5. Rappaport, S.M.: Exposure assessment strategies. In Exposure Assessment for Occupational Epidemiology and Hazard Control, S.M. Rappaport and T.L. Smith (eds.), pp. 219-250. Chelsea, Michigan: Lewis Publishing Co., 1990.

6. Truchon, G., R. Tardif, P.O. Droz, G. Charest-Tardif and G. Pierrehumbert: Biological exposure indicators: Quantification of biological variability using toxicokinetic modeling. $J$. Occup. Environ. Hyg. 3:137-143 (2006).

7. Truchon, G., R. Tardif, P.O. Droz, G. Charest-Tardif, G. Pierrehumbert, and D. Drolet: Quantification of biological variability using modeling - Development of a strategy guide for biological exposure monitoring Quantification de la Variabilité Biologique à l'aide de la Modélisation - Élaboration d'un Guide de Stratégie pour la Surveillance Biologique de l'Exposition] (Rapport R-337). [Report] Montréal: IRSST, 2003 (in French).

8. Droz, P.O., and M.M. Wu,: Biological monitoring strategies. In Exposure Assessment for Epidemiology and Hazard Control, S.M. Rappaport, and T.J. Smith, (eds.), pp. 251-270. Chelsea, Michigan: Lewis Publishers, 1990.

9. Tardif, R., G. Truchon, P.O. Droz, G. Charest-Tardif, and G. Pierrehumbert: Impact of human variability on the biological monitoring of exposure to toluene I. Physiologically based toxicokinetic modelling. Toxicol. Lett. 134:155-163 (2002). 
10. Pierrehumbert, G., P.O. Droz, R. Tardif, G. Charest-Tardif, and G. Truchon: Impact of human variability on the biological monitoring of exposure to toluene, phenol, lead, and mercury II. Compartmental based toxicokinetic modelling. Tox. Lett. 134:165-175 (2002).

11. Truchon, G.: Biological monitoring guide -Sampling and Interpretation of Results [Guide de Surveillance Biologique - Prélèvement et Interprétation des Résultats], 6th edition. (Rapport T03) [ Report] Montréal: IRSST, 2004.

12. Laparé, S., R. Tardif, and J. Brodeur: Effect of various exposure scenarios on the biological monitoring of organic solvents in alveolar air. II. 1,1,1-trichloroethane and trichloroethylene. Int. Arch. Occup. Environ. Health. 67:375-394 (1995).

13. Thomas, R. S., P.L. Bigelow, T.J. Keefe, and R.S.H. Yang: Variability in biological exposure indices using physiologically based pharmacokinetic modeling and Monte Carlo simulation. Am. Ind. Hyg. Assoc. J. 57:23-32 (1996).

14. American Conference of Governmental Industrial Hygienists (ACGIH ${ }^{\circledR}$ ): Documentation of the Threshold Limit Values and Biological Exposure Indices, 7th edition. Cincinnati: ACGIH, 2009.

15. World Health Organization (WHO): "Environmental Health Criteria Series, International Program on Chemical Safety (IPCS)". [Online] Available at http://www.inchem.org/ (Accessed September, 2009). 
16. Bingham, E., B. Cohrssen, and C.H. Powell: Patty's industrial hygiene and toxicology, $5^{\text {th }}$ edition. Danver:Wiley-Interscience publication, 2001.

17. U.S. Environmental Protection Agency (U.S. EPA): "Risk Assessment Guidance for Superfund: Volume III - Part A, Process for Conducting Probabilistic Risk Assessment," Appendix D. OSWER Directive No. 9285.7-45. 2001. 27 p. [Online] Available at http://www.epa.gov/oswer/riskassessment/rags3adt/ (Accessed September 24, 2009).

18. Daniel, W. W.: Biostatistics: a foundation for analysis in the health sciences, John Wiley \& sons, (eds.), pp. 181-183. New York, NY, 1999.

19. Consolazio, C.F., R.E. Johnson, and L.J. Pecosa: Physiological measurements of metabolic functions in man, pp. 453-480. New York: McGraw-Hill, 1969.

20. "Regulation respecting the Quality of the work environment" (RQMT) -, Regulation respecting the quality of the work environment (L.R.Q., c S.-2.1) and An Act respecting occupational health and safety (L.R.Q., c. Q-2), Annex A. Government of Québec. 1981. 33 p. [Online] Available at http://www2.publicationsduquebec.gouv.qc.ca/dynamicSearch/telecharge.php?type=3\&file=/S_2 -1/S2_1R15.htm.

21. Deutsche Forschungsgemeinschaft (DFG): List of MAK Values. Commission for the Investigation of Health Hazards of Chemical Compounds in the Work Area (Report N36). [Report] Weinheim: Wiley-VCH Verlag GmbH \& Co. KGaA, 2000. 
22. Rappaport, S.M., E. Symanski, J.W. Yager, and L.L. Kupper: The relationship between environmental monitoring and biological markers in exposure assessment. Environ. Health Perspect. 103:49-54 (1995).

23. Symanski, E., G. Sällsten, and L. Barregard: Variability in airborne and biological measures of exposure to mercury in the chloralkali industry: Implications for epidemiologic studies. Environ. Health Perspect. 108:569-573 (2000).

24. Tardif, R.; G. Charest-Tardif, J. Brodeur, and K. Krishnan: Physiologically based pharmacokinetic modeling of a ternary mixture alkyl benzenes in rats and humans. Toxicol. Appl. Pharmacol. 144(1):120-134 (1997).

25. Mann, S., P.O. Droz, and M. Vahter: A physiologically based pharmacokinetic model for arsenic exposure II. Validation and application in humans. Toxicol. Appl. Pharmacol. 140:471486 (1996).

26. Fiserova-Bergerova, V.: Modeling of Inhalation Exposure to Vapors: Uptake, Distribution, and Elimination. Boca Raton: CRC Press, 1983.

27. Johanson, G.: An overview of glycol ethers metabolism and toxicokinetics. Occup. Hyg. 2:524 (1996). 
28. Gargas, M. L., T.R. Tyler, L.M. Sweeney, R.A. Corley, K.K. Weitz, T.J. Mast, D.J. Paustenbach, and S.M. Hays: A toxicokinetic study of inhaled ethylene glycol ethyl ether acetate and validation of a physiologically based pharmacokinetic model for rat and human. Toxicol. Appl. Pharmacol. 165:63-73 (2000).

29. Green, C. E., G.R. Gordon, P.M. Cohen, H.W. Nolen, J.H. Peters, and C. A. Tyson: In vitro metabolism of glycol ethers and rat hepatocytes. Occup. Hyg. 2:67-75 (1996).

30. Hjelm, E. W., M. Hagberg, A. Iregren, and A. Löf: Exposure to methyl isobutyl ketone: toxicokinetics and occurence of irritative and CNS symptoms in man. Int. Arch. Occup. Environ. Health. 62:19-26 (1990).

31. Araki, S., H. Aono, K. Yokoyama, and K. Murata: Filterable plasma concentration, glomerular filtration, tubular balance, and renal clearance of heavy metals and organic substances in metal workers. Arch. Environ. Health. 41(4):216-221 (1986).

32. Sato, A., and T. Nakajima: Partition coefficients of some aromatic hydrocarbons and ketones in water, blood and oil. Br. J. Ind. Med. 36:231-234 (1979).

33. Gargas, M. L., R.J. Burgess, D.E. Voisard, G.H. Cason, and M. E. Andersen: Partition coefficients of low-molecular-weight volatile chemicals in various liquids and tissues. Toxicol. Appl. Pharmacol. 98(1):87-99 (1989). 
34. Baelum, J., M. Dossing, S.H.L. Hansen, and G.R. Lundqvist: Hippuric acid and orthocresol as indices of toluene exposure. Ann. Am. Conf. Ind. Hyg. 12:305-309 (1985).

35. Cohen, B.S., and S.V. Hering: Air Sampling Instruments for Evaluation of Atmospheric Contaminants, 8th edition. Cincinatti: ACGIH, 1995.

36. Clarkson, T. W., L. Friberg, G.F. Nordberg, and P.R. Sager: Biological Monitoring of Toxic Metals. New York: Plenum Press, 1988.

37. Uhl, S., P. Schmid, and C. Schlatter: Pharmacokinetics of pentachlorophenol in man. Arch. Toxicol. 58(3):182-186 (1986). 
FIGURE 1. Toxicokinetic model scheme ${ }^{(10)}$

Where $i$ represents a substance $i$; M1, metabolite 1 of substance $i$; and M2, metabolite 2 . 
FIGURE 2. Relationship between half-life (hours) and the predicted environmental variability $\left(\mathrm{BV}_{\mathrm{E}}\right)$ for low (GSD of 1.5) and average (GSD of 2.0) exposures

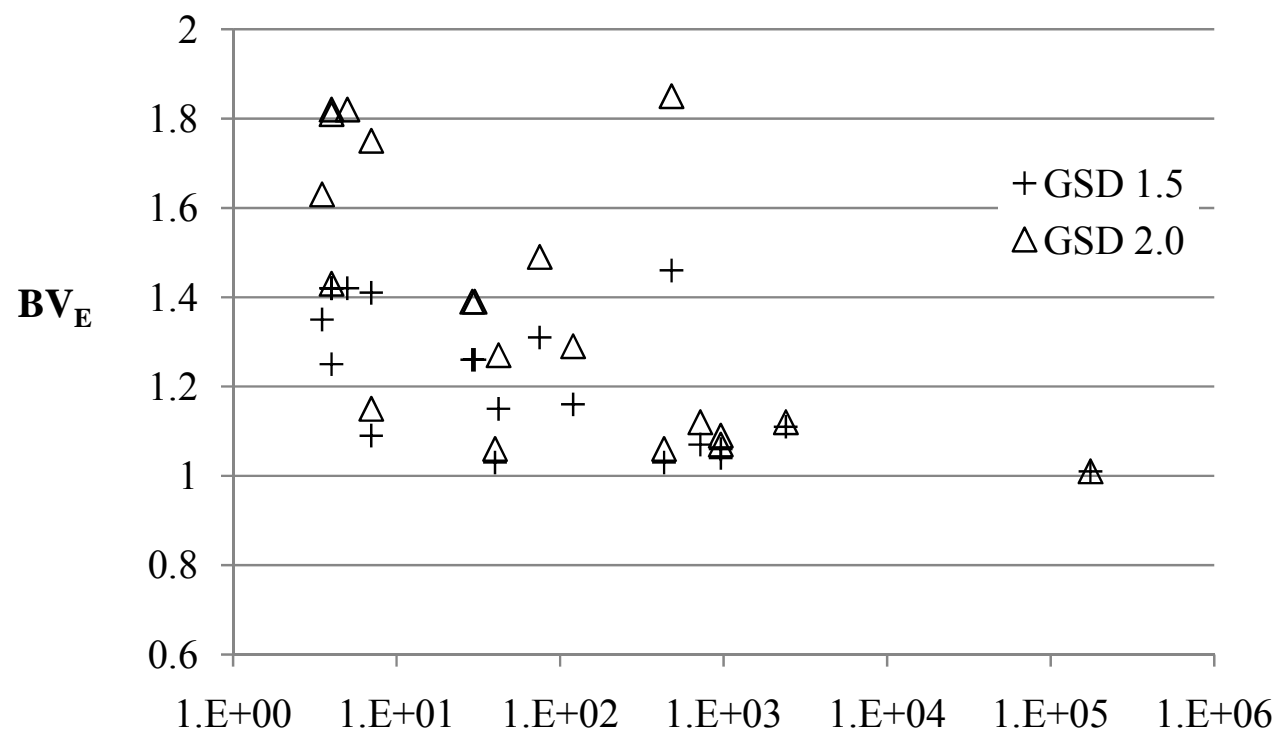

Half-life [h]

Points represent one of the 14 substances analyzed for each exposure level 
Table I. General physiological parameters used in the simulations: Coefficient of variation and type of distribution

\begin{tabular}{|c|c|c|c|c|c|}
\hline Parameters & Symbol & At rest & At $50 \mathrm{~W}$ & Distribution $^{b}$ & $\mathrm{CV}^{\mathrm{c}}(\%)$ \\
\hline Cardiac output $\left(1 / \mathrm{h}_{\text {per }} \mathrm{kg}^{0.7}\right)$ & $\mathrm{Q}_{\mathrm{c}}$ & $18.0^{(11)}$ & $30.8^{(11)}$ & $\mathrm{L}^{(11)}$ & $30^{(11)}$ \\
\hline Alveolar ventilation $\left(1 / \mathrm{h}_{\text {per }} \mathrm{kg}^{0.7}\right)^{\mathrm{a}}$ & $\mathrm{V}_{\mathrm{alv}}$ & $18.0^{(11)}$ & $67.6^{(11)}$ & - & - \\
\hline Body weight (kg) & $\mathrm{BW}$ & 70 & 70 & $\mathrm{~L}^{(11)}$ & $13^{(11)}$ \\
\hline Creatinine excretion $\left(\mu \mathrm{mol} / \mathrm{h}\right.$ per $\left.\mathrm{kg}^{0.9}\right)$ & $\mathrm{K}_{\mathrm{cr}}$ & $12.6^{(12)}$ & $12.6^{(12)}$ & $\mathrm{N}^{(11)}$ & $30^{(11)}$ \\
\hline Urine output $\left(\mathrm{ml} / \mathrm{h}\right.$ per $\left.\mathrm{kg}^{0.82}\right)$ & $\mathrm{k}_{\mathrm{ur}}$ & $1.848^{(12)}$ & $1.848^{(12)}$ & $\mathrm{L}^{(11)}$ & $20^{(11)}$ \\
\hline $\begin{array}{l}\text { Permeability coefficient and affinity } \\
\text { coefficient between media } \boldsymbol{i} \text { and } \\
\text { media } \boldsymbol{i}\end{array}$ & $P_{P}, P_{M}, P_{i: j}$ & d & $\mathrm{d}$ & $\mathrm{L}^{(11)}$ & $11^{(11)}$ \\
\hline $\begin{array}{l}\text { Volume of compartment } i \text { expressed } \\
\text { as fraction of body weight (BW) }\end{array}$ & $\mathrm{FV}_{\mathrm{i}}$ & d & $\mathrm{d}$ & $\mathrm{N}^{(11)}$ & $20^{(11)}$ \\
\hline $\begin{array}{l}\text { Cardiac output fractions to the } \\
\text { corresponding peripheral tissues }\end{array}$ & $\mathrm{BF}_{\mathrm{i}}$ & d & d & $\mathrm{N}^{(11)}$ & $20^{(11)}$ \\
\hline Metabolites fractionation & $\mathrm{F}_{2} / \mathrm{F}_{1}$ & d & $\mathrm{d}$ & $\mathrm{L}^{(11)}$ & $35^{(11)}$ \\
\hline Clearance and excretion constant & $\mathrm{RC}, \mathrm{k}_{\mathrm{u},} \mathrm{k}_{\mathrm{f}}$ & $\mathrm{d}$ & $\mathrm{d}$ & $\mathrm{L}^{(11)}$ & $30^{(11)}$ \\
\hline Michaelis Menten constant $(\mu \mathrm{mol} / \mathrm{l})$ & $\mathrm{K}_{\mathrm{Mi}}$ & d & $\mathrm{d}$ & $\mathrm{L}^{(11)}$ & $20^{(11)}$ \\
\hline Maximum rate $\left(\mu \mathrm{mol} / \mathrm{h}\right.$ per $\left.\mathrm{kg}^{0.75}\right)$ & $\mathrm{V}_{\mathrm{Mi}}$ & d & $\mathrm{d}$ & $\mathrm{L}^{(11)}$ & $50^{(11)}$ \\
\hline
\end{tabular}

${ }^{\text {a }}$ Calculated proportionally to cardiac output individual values.

${ }^{\mathrm{b}}$ Distribution type: Log normal (L) or Normal (N).

${ }^{c}$ Coefficient of variation for log normally distributed parameters is obtained from GSD $\left(\mathrm{CV}=\sqrt{ } \mathrm{e}^{(\mathrm{GSD}) 2}-1\right)$

${ }^{\mathrm{d}}$ Depends on the chemical, see Table IV (in Appendix) 
Table II. Comparison between the biological exposure index $\left(\mathrm{BEI}^{\circledR}\right)$ proposed by the ACGIH (2009) and the predicted biomarker values corresponding to an $8 \mathrm{~h}$-TWA inhalation exposure to the $\mathrm{TLV}^{\circledR}$, as predicted with the toxicokinetic models

\begin{tabular}{|c|c|c|c|c|c|}
\hline $\begin{array}{l}\text { Compound/biological } \\
\text { parameter }\end{array}$ & Sampling time & $\begin{array}{l}\text { Exposure } \\
\text { level }\left(O E L^{\circledR}\right) \\
\left(\mathbf{m g} / \mathbf{m}^{3}\right)^{(11)}\end{array}$ & Units & $\mathbf{B E} \mathbf{I}^{(14,19)}$ & $\begin{array}{l}\text { CBTK } \\
\text { model }\end{array}$ \\
\hline \multicolumn{6}{|l|}{ Arsenic } \\
\hline urinary inorganic arsenic & End of workweek & 0.01 & $\mathrm{nmol} / \mathrm{mmol}$ creat & 52 & 92 \\
\hline \multicolumn{6}{|l|}{ Cadmium } \\
\hline urinary cadmium & Discretionary & \multirow{2}{*}{0.01} & $\mathrm{nmol} / \mathrm{mmol}$ creat & 5 & 4.7 \\
\hline blood cadmium & Discretionary & & $\mathrm{nmol} / 1$ & 45 & 42 \\
\hline \multicolumn{6}{|l|}{ Carbon monoxide } \\
\hline carboxyhemoglobine & End of shift & 25 & $\%$ of hemoglobin & 3.5 & 4.7 \\
\hline \multicolumn{6}{|l|}{ Chromium } \\
\hline urinary chromium & Increase during shift & \multirow{2}{*}{0.05} & $\mathrm{nmol} / \mathrm{mmol}$ creat & 22 & 20 \\
\hline urinary chromium & End of workweek & & $\mathrm{nmol} / \mathrm{mmol}$ creat & 55 & 90 \\
\hline \multicolumn{6}{|l|}{ Cobalt } \\
\hline urinary cobalt & End of workweek & \multirow{2}{*}{0.02} & $\mathrm{nmol} / \mathrm{l}$ & 255 & 166 \\
\hline blood cobalt & End of workweek & & $\mathrm{nmol} / \mathrm{l}$ & 17 & 11 \\
\hline \multicolumn{6}{|l|}{ Ethylbenzene } \\
\hline urinary mandelic acid & End of workweek & 434 & $\mu \mathrm{mol} / \mathrm{mmol}$ creat & 0.7 & 1.08 \\
\hline \multicolumn{6}{|c|}{ Ethyleneglycol monomethylether } \\
\hline \multicolumn{6}{|l|}{ Fluorides } \\
\hline urinary fluorides & Beginning of workweek & 2.5 & $\mu \mathrm{mol} / \mathrm{mmol}$ creat & 18 & 18 \\
\hline urinary fluorides & End of workweek & 2.5 & $\mu \mathrm{mol} / \mathrm{mmol}$ creat & 60 & 56 \\
\hline \multicolumn{6}{|l|}{ Lead } \\
\hline Blood lead & Discretionary & $0.15^{\mathrm{b}}$ & $\mathrm{nmol} / 1$ & 2.42 & 2.69 \\
\hline \multicolumn{6}{|l|}{ Mercury } \\
\hline urinary mercury & Beginning of workweek & 0.025 & $\mathrm{nmol} / \mathrm{mmol}$ creat & 20 & 17 \\
\hline
\end{tabular}




\section{Methyl isobutyl ketone}

urinary methylethylketone

end of shift

205

$\mu \mathrm{mol} / 1$

20

41

Pentachlorophenol

free PCP in plasma

end of shift

$\mu \mathrm{mol} / 1$

19

14

urinary total PCP

beginning of shift

0.5

$\mathrm{nmol} / \mathrm{mmol}$ creat

850

772

\section{Phenol}

urinary phenol

end of shift

19

$\mu \mathrm{mol} / \mathrm{mmol}$ creat $\quad 300$

355

\section{Toluene}

urinary o-cresol

end of shift

188

$\mu \mathrm{mol} / \mathrm{mmol}$ creat $\quad 0.72$

0.99

${ }^{a}$ Excretions corrected by creatinine are calculated using a creatinine excretion of $1 \mathrm{~g} / 1$

${ }^{\mathrm{b}}$ According to the RQMT of Quebec ${ }^{(20)}$ 
Table III. Predicted biological $\left(\mathrm{BV}_{\mathrm{B}}\right)$, environmental $\left(\mathrm{BV}_{\mathrm{E}}\right)$ and total variability $\left(\mathrm{BV}_{\mathrm{T}}\right)$ for two exposure patterns $(\mathrm{GSD}$ of 1.5 and $\mathrm{GSD}$ of 2.0$)$

\begin{tabular}{|c|c|c|c|c|c|c|c|c|c|}
\hline \multirow[t]{2}{*}{ Chemical } & \multirow[t]{2}{*}{ Biological indicator } & \multirow[t]{2}{*}{ Half-life $^{c}$} & \multirow[b]{2}{*}{$\mathbf{B V}_{\mathbf{B}}$} & \multicolumn{3}{|c|}{ GSD of $1.5^{\mathrm{a}}$} & \multicolumn{3}{|c|}{ GSD of $2.0^{b}$} \\
\hline & & & & $\mathbf{B V}_{\mathbf{E}}$ & $\mathbf{B V}_{\mathbf{T}}$ & $\mathbf{U C \mathbf { I } _ { \mathbf { T } }}{ }^{\mathrm{d}}$ & $\mathbf{B V}_{\mathbf{E}}$ & $\mathbf{B V}_{\mathbf{T}}$ & $\mathbf{U C I _ { T }}{ }^{\mathrm{d}}$ \\
\hline Arsenic & $\begin{array}{l}\text { Inorganic arsenic and } \\
\text { urinary metabolites }\end{array}$ & $5 \mathrm{~d}$ & 1.49 & 1.16 & 1.53 & 2.3 & 1.29 & 1.60 & 2.5 \\
\hline \multirow{2}{*}{ Cadmium } & Urinary cadmium & $20 y$ & 1.68 & 1.01 & 1.64 & 2.6 & 1.01 & 1.64 & 2.6 \\
\hline & Blood cadmium & $100 \mathrm{~d}$ & 1.24 & 1.11 & 1.23 & 1.5 & 1.12 & 1.24 & 1.5 \\
\hline \multirow[t]{2}{*}{ Chromium } & $\begin{array}{l}\text { Urinary chromium } \\
\text { (delta) }\end{array}$ & $7 \mathrm{~h}, \underline{15-30 \mathrm{~d}}, 3-5 \mathrm{y}$ & 1.60 & 1.46 & 1.81 & 3.2 & 1.85 & 2.15 & 4.5 \\
\hline & Blood chromium (end) & $\underline{7 h}, 15-30 \mathrm{~d}, 3-5 \mathrm{y}$ & 1.42 & 1.09 & 1.41 & 2.0 & 1.15 & 1.43 & 2.0 \\
\hline \multirow{2}{*}{ Cobalt } & Urinary cobalt & $\underline{30 \mathrm{~h}}, 10 \mathrm{y}$ & 1.40 & 1.26 & 1.55 & 2.4 & 1.39 & 1.67 & 2.7 \\
\hline & Blood cobalt & $\underline{29 \mathrm{~h}}, 52 \mathrm{~d}$ & 1.19 & 1.26 & 1.40 & 1.9 & 1.39 & 1.54 & 2.3 \\
\hline \multirow{2}{*}{$\begin{array}{l}\text { Ethyleneglycol } \\
\text { monomethylether } \\
\text { Ethylbenzene }\end{array}$} & $\begin{array}{l}\text { Urinary 2-ethoxyacetic } \\
\text { acid }\end{array}$ & $42 \mathrm{~h}$ & 1.46 & 1.15 & 1.49 & 2.2 & 1.27 & 1.56 & 2.4 \\
\hline & Urinary mandelic acid & $3.5 \mathrm{~h}$ & 1.52 & 1.35 & 1.67 & 2.7 & 1.63 & 1.92 & 3.6 \\
\hline \multirow[t]{2}{*}{ Fluorides } & $\begin{array}{l}\text { Urinary fluorides } \\
\text { (beginning) }\end{array}$ & $4 \mathrm{~h}, \underline{18 \mathrm{~d}, 8 \mathrm{y}}$ & 1.63 & 1.03 & 1.72 & 2.9 & 1.06 & 1.73 & 2.9 \\
\hline & Urinary fluorides (end) & $\underline{4 \mathrm{~h}}, 18 \mathrm{~d}, 8 \mathrm{y}$ & 1.46 & 1.25 & 1.55 & 2.4 & 1.43 & 1.70 & 2.8 \\
\hline \multirow{2}{*}{ Mercury } & $\begin{array}{l}\text { Urinary inorganic } \\
\text { mercury }\end{array}$ & $40 d$ & 1.79 & 1.04 & 1.79 & 3.1 & 1.07 & 1.80 & 3.2 \\
\hline & $\begin{array}{l}\text { Blood inorganic } \\
\text { mercury }\end{array}$ & $75 \mathrm{~h}$ & 1.34 & 1.31 & 1.44 & 2.0 & 1.49 & 1.59 & 2.5 \\
\hline $\begin{array}{l}\text { Methyl isobutyl } \\
\text { ketone }\end{array}$ & Urinary MIBK & $7 \mathrm{~h}$ & 1.55 & 1.41 & 1.75 & 3.0 & 1.75 & 2.06 & 4.1 \\
\hline Carbon monoxide & $\mathrm{COHb}$ & $5 \mathrm{~h}$ & 1.14 & 1.42 & 1.47 & 2.1 & 1.82 & 1.88 & 3.4 \\
\hline Pentachloropheno & Plasmatic PCP & $30 \mathrm{~d}$ & 1.38 & 1.07 & 1.38 & 1.9 & 1.12 & 1.40 & 1.9 \\
\hline 1 & Urinary PCP & $\underline{40 h}, 4 \mathrm{~d}, 72 \mathrm{~d}$ & 1.40 & 1.03 & 1.46 & 2.1 & 1.06 & 1.46 & 2.1 \\
\hline Phenol & Urinary Phenol & $\overline{4 h}$ & 1.52 & 1.42 & 1.72 & 2.9 & 1.82 & 2.08 & 4.2 \\
\hline Lead & $\begin{array}{l}\text { Blood lead } \\
\text { (discretionary) }\end{array}$ & $\underline{40 \mathrm{~d}}, 20 \mathrm{y}$ & 1.40 & 1.06 & 1.35 & 1.8 & 1.09 & 1.36 & 1.8 \\
\hline Toluene & Urinary ortho-cresol & $4 \mathrm{~h}$ & 1.63 & 1.42 & 1.82 & 3.2 & 1.81 & 2.16 & 4.4 \\
\hline
\end{tabular}


${ }^{a}$ small variations in the exposure scenario (GSD of 1.5).

${ }^{\mathrm{b}}$ average variations in the exposure scenario (GSD of 2.0).

${ }^{\mathrm{c}}$ Underlined value indicate the dominant half-life at time of sampling $(\mathrm{d}=\mathrm{day}, \mathrm{h}=$ hour, $\mathrm{y}=\mathrm{year})$

${ }^{\mathrm{d}}$ Upper confidence index (95\%) of each bioindicator calculated from simulated total variability in the bioindicators due to both the interindividual variability and exposure variability 